\title{
Is Changing the Minimum Legal Drinking Age an Effective Policy Tool?
}

\author{
Nicolai Brachowicz \\ Centre for Research in Health and Economics \\ Universitat Pompeu Fabra \\ Judit Vall Castello \\ Department of Economics \\ Universitat de Barcelona \\ \& IEB \& CRES-UPF
}

\begin{abstract}
In year 1991 regional governments in Spain started a period of implementation of a law that rose the Minimum Legal Drinking Age from 16 to 18 years old. To evaluate the effects of this change on consumption of legal drugs and its related morbidity outcomes, we construct a regional panel dataset on alcohol consumption and hospital entry registers and compare variation in several measures of prevalence between the treatment group (16-18 years old) and the control group (20-22 years old). Our findings show important differences by gender.

Our main result regarding overall drinking prevalence shows a reduction of $-21.37 \%$ for the subsample that includes males and females altogether. This effect on drinking is mainly driven by a reduction of $-44.43 \%$ in mixed drinks and/or liquors drinking prevalence corresponding to the subsample of males. No causal effects regarding overall smoking prevalence, hospitalizations due to alcohol overdose or motor vehicle traffic accidents were found.

To our knowledge, this is the first paper providing evidence on gender-based differences to policies aimed at reducing alcohol consumption. Our results have important policy implications for countries currently considering changes in the Minimum Legal Drinking Age.
\end{abstract}

Keywords: evaluation of public policies; health economics; minimum legal drinking age; triple differences; drug consumption. 


\section{Introduction}

Abuse of alcohol consumption and its undesired and fatal consequences have been studied from multiple perspectives ranging from direct effects on individuals (Carpenter, 2004a; Mann, Smart, \& Govoni, 2003; Rosenberg, Ventura, Maurer, Heuser, \& Freedman, 1996; Wagenaar \& Toomey, 2002) to negative externalities exerted on the society as a whole (Carpenter, 2005, 2007; Markowitz, 2000, 2005). According to the latest figures provided by the Report on Survey on Drugs Use in Secondary Schools in Spain (Observatorio Español de las Drogas y las Adicciones (OEDT). Ministerio de Sanidad y Servicios Sociales e Igualdad, 2016), corresponding to survey years 2014/2015, the average age at first use of alcohol considering weekly consumption, has remained almost invariable since year 1996 at around 15 years old. Moreover, around $48 \%, 61 \%$, and $74 \%$ of youngsters, aged 14,15 , and 16 respectively, declared to have consumed alcohol during the last 30 days in years $2014 / 2015$. There is a growing body of evidence pointing at the limitation of access to alcohol consumption as an effective policy tool for preventing unhealthy habits and fatal consequences (Carpenter, 2004b; Carpenter \& Dobkin, 2011; Dee, 1999; Deza, 2015; Yörük \& Yörük, 2011, 2013). In an effort to reduce the prevalence of alcohol consumption and its undesired outcomes, regional authorities in Spain decided to restrict the access of teenagers to alcohol by increasing the Minimum Legal Drinking Age (hereafter, MLDA) from 16 to 18 years old. Figure 1 shows a chronological description of the implementation of the new MLDA in Spain.

Figure 1: Spain - Implementation of the New Minimum Drinking Age

(Time Scope)

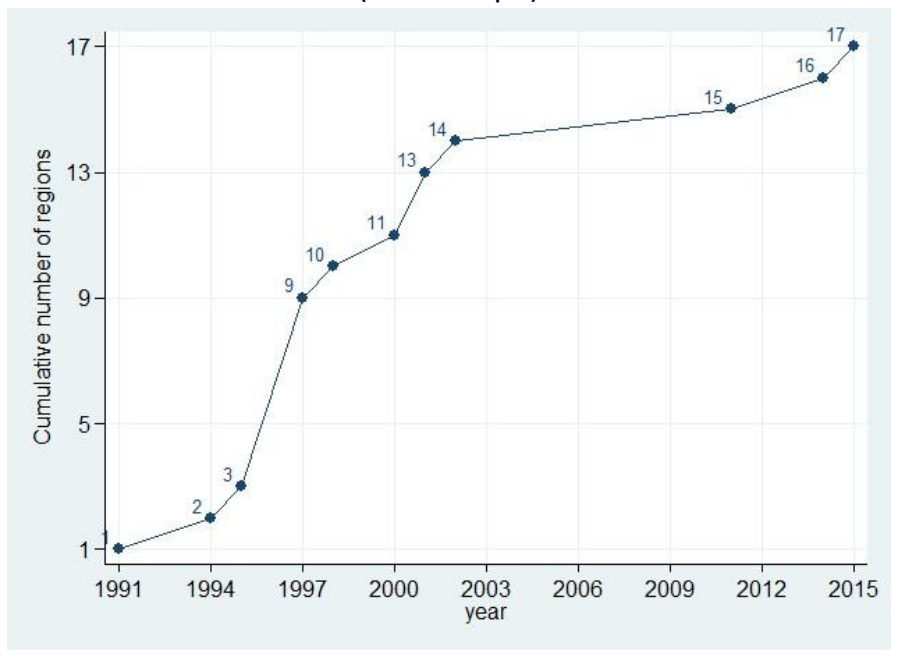

Source: Official Bulletins.

Having a uniform MLDA threshold at 18 years old in all seventeen regions took more than two decades, although most of them implemented the legal modification during the period 1994-2002. Until year 1991 the MLDA in all regions was 16 years old. On April 1991 the Region of Navarra was the first to rise the MLDA to 18 years old. This was followed progressively by Region of Castilla y León in 1994, and Region of Castilla La Mancha in 1995. In year 1997 most of the regions, namely Andalucía, Canarias, Cantabria, Comunitat Valenciana, Extremadura, and Murcia, updated its corresponding law. Region of País Vasco implemented the new threshold in 1998, Madrid in year 2000, Region of La Rioja and Region of Aragón in 2001, and the Region of Catalunya in 2002. Late joiners, namely Galicia, Baleares, and Asturias shifted the threshold in 2011, 2014, and 2015, respectively. ${ }^{1}$ Table C1, in Appendix C provides detailed regional information and references to official bulletins.

\footnotetext{
${ }^{1}$ Prohibition included all drink types regardless alcoholic degrees for most of the regions. However, Regions of Castilla y León, and Comunitat Valenciana kept permitting teenagers aged 16 or older to consume alcoholic drinks up to $18^{\circ}$ alcoholic degrees until year 2007 and 2002, respectively. In order to provide conservative estimates, we consider year of partial ban, when proceeds, as if it were the case of a full prohibition.
} 
Our empirical study takes advantage of this quasi-natural experiment using a triple differences method, with the aim of evaluating and quantifying the prospective effects of changing the MLDA on the consumption of legal drugs (i.e. alcoholic drinks and cigarettes) and related morbidity outcomes such as hospitalizations due to alcohol overdose and hospitalizations due to motor vehicle traffic accidents.

\section{Methods}

\subsection{Triple Differences}

Outcomes variables for model 1 for the treated group (16-18 year olds), $y_{t r}^{\text {treated }}$, and for model 2 for control group (20-22 year olds), $y_{t r}{ }^{\text {control }}$, are constructed as measures of prevalence or incidence for each region/year before, during and after policy implementation. However, for the Triple Difference model (Equation 3), we constructed each region/year outcome variable as the difference in outcomes between treated and control group, $y_{t r}^{\text {treated }}-y_{t r}^{\text {control }}$. Our econometric models are as follows:

$$
\begin{gathered}
y_{t r}{ }^{\text {treated }}=\beta_{0}+\beta_{1} * d \_ \text {policy } y_{t r}+\alpha_{r}+\psi_{t}+\varepsilon_{t r} \\
y_{t r}{ }^{\text {control }}=\beta_{0}+\beta_{1} * d \_ \text {policy } y_{t r}+\alpha_{r}+\psi_{t}+\varepsilon_{t r} \\
y_{t r}{ }^{\text {treated }}-y_{t r}{ }_{t r}^{\text {control }}=\beta_{0}+\beta_{1} * d \_p o l i c y_{t r}+\alpha_{r}+\psi_{t}+\varepsilon_{t r}
\end{gathered}
$$

In all three models, for each region our dummy policy variable, $d \_$policy $y_{t r}$ takes on value 1 for the year of implementation and subsequent years, and 0 for all years prior to the year of the legal change. Also, all models include region fixed-effects $\left(\alpha_{r}\right)$, year fixed-effects $\left(\psi_{t}\right)$, as well as a constant $\left(\beta_{0}\right)$ and an error term $\left(\varepsilon_{t r}\right)$. Standard errors were clustered at the regional level and computed using wild-bootstrapping (Bertrand, Duflo, \& Mullainathan, 2004). Furthermore, regional size differences are taken into account by using as analytical weights the population of the corresponding cohort, per each region and year, for models 1 and 2; or the sum of the corresponding population amongst treated and control groups, for the Triple Difference model.

\subsection{Analysis}

The identification on which our causal Triple Differences estimates are based is the timing of the policy implementation. We estimate Equation 1 and Equation 2 for the subsample of treated individuals (aged 1618) and the subsample of control individuals (aged 20-22), respectively. In the first case, the effects of the policy are identified by exploiting the region-level timing in MLDA laws while the second case represents a falsification test. Finally, in our third specification with the outcome variable as the difference in outcomes between treated and control groups, we estimate the coefficient of interest that would quantify the causal effect of this policy reform on each of the outcome variables, a statistically significant estimate of $B_{1}$. The advantage of this three-step procedure is that we are able to control the source of identification while performing an explicit falsification test. This is a triple difference estimate and is equivalent to including region-by-year fixed effects in the disaggregated sample.

\section{Data}

The National Health Survey, (Encuesta Nacional de Salud or ENS), and the Hospital Morbidity Survey (Encuesta de Morbilidad Hospitalaria or EMH) are the two main data sources used in this study. While ENS available waves correspond to years 1991, 1993, 1995, 1997, 2001, 2003, 2004, 2006, and 2007, EMH provides data for all years between the 1991-2007 period. From these foregoing sources, we extracted data for the same thirteen regions that shifted the MLDA between years 1994-2002 (see Figure 2). Data for the 
four remaining regions that shifted the MLDA in years, 1991, 2011, 2014, 2015, were not included due to a lack of enough pre or post policy survey datasets. Three regional panel datasets were prepared, the first including males and females altogether, the second considering only males, and the third including just females. We only considered individuals aged 16-18 or 20-22.

Figure 2: Spain - Implementation of the New Minimum Drinking Legal Age

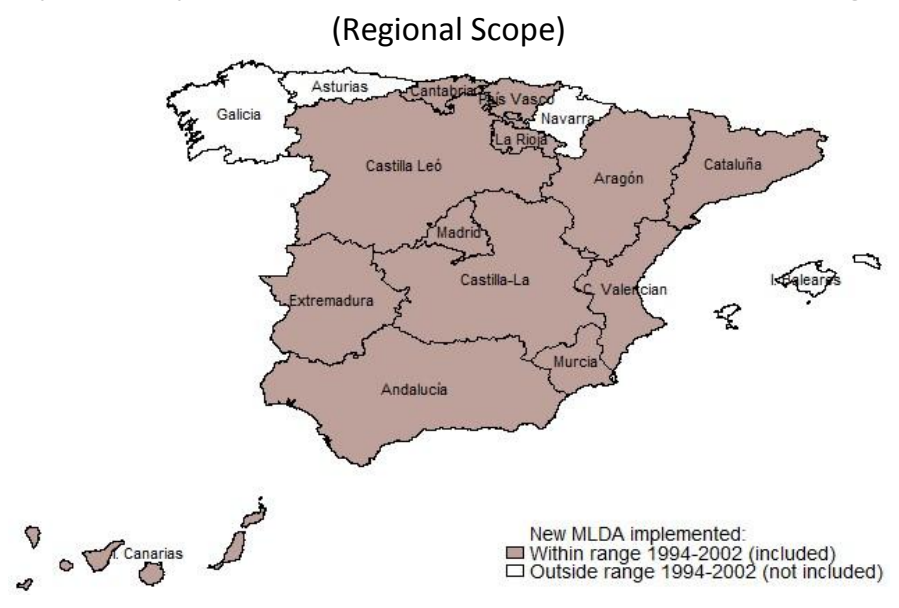

Source: Official Bulletins.

Data regarding regional population was extracted from the Population Statistics Database provided by the National Statistics Institute (Instituto Nacional de Estadística or INE). ${ }^{2}$

Regarding ENS, our main outcome variables measure overall drinking prevalence and overall smoking prevalence. The drinking variable equals 1 if the individual has drunk alcohol during the last 2 weeks and zero otherwise ${ }^{3}$. Unfortunately, we cannot measure the incidence of binge drinking as we do not have a measure of the number of drinks that is consistent throughout the waves included in the analysis. The smoking variable is 1 if the individual smokes nowadays and zero otherwise.

With regard to EMH datasets, our outcome variables are incidence of hospitalization by main diagnostic related to alcohol consumption (per 1000 individuals), and incidence of hospitalizations by traffic accidents (per 1000 individuals) ${ }^{4}$. It is noteworthy to mention that $\mathrm{EMH}$ only includes as observations inpatient hospital stays cases.

\section{Results}

\subsection{Overall Prevalence}

Table 1 shows estimated coefficients for the case of overall drinking prevalence. First column in Panel A reports a statistically significant reduction corresponding to our first regression model (16-18 year olds) and null effects for second column corresponding to our falsification test estimated by our second model. For our third model, third column shows a Triple Difference estimated coefficient of -0.10 , statistically significant at the $1 \%$ level, corresponding to a causal effect of $-21.37 \%$ for the subsample of males and females altogether.

For the case of overall smoking prevalence, Table A1 in Appendix Section A shows that, although the impacts for the treated group are negative, none of the estimated coefficients is statistically significant.

\footnotetext{
${ }^{2}$ In Appendix C, Table C1 shows precise implementation dates; Table C2 depicts a summary of descriptive statistics for ENS and EMH waves; finally, Table C3 lists diseases (diagnoses) considered for the case of morbidity outcomes.

${ }^{3}$ For years 2003/2004 the question on overall drinking prevalence asks if the individual has drunk alcohol during the last 12 months instead of during the last 2 weeks.

${ }^{4}$ Lack of enough observations for the treated group (16-18 age cohort) prevented us from running analogue analysis for the case of incidence of hospitalizations by suicides.
} 
Figures B1 and B2 in Appendix Section B provides graphical evidence on the evolution of these outcomes for the treated and control groups before, during and after the MLDA threshold shift.

Table 1: Overall Drinking Prevalence

Panel A: Both Genders

\begin{tabular}{lccc}
\hline & $(1)$ & $(2)$ & $(3)$ \\
VARIABLES & $16-18$ yo & $20-22$ yo & Triple Difference \\
\hline Dummy policy & $-0.09^{* *}$ & 0.01 & $-0.10^{* * *}$ \\
& $(0.04)$ & $(0.06)$ & $(0.04)$ \\
& & & \\
Observations & 104 & 104 & 104 \\
R-squared & 0.31 & 0.47 & 0.36 \\
Mean Before Policy & 0.48 & 0.64 & - \\
$\quad$ Implied impact of New MLDA in \% & & & -21.37 \\
\end{tabular}

Panel B: Males

\begin{tabular}{lccc}
\hline VARIABLES & $(1)$ & $(2)$ & $(3)$ \\
\hline \multirow{2}{*}{$\begin{array}{l}\text { Dummy policy } \\
\text { 16-18yo }\end{array}$} & $20-22$ yo & Triple Difference \\
& -0.02 & 0.03 & -0.05 \\
& $(0.06)$ & $(0.04)$ & $(0.06)$ \\
Observations & 104 & 103 & 103 \\
R-squared & 0.28 & 0.23 & 0.22 \\
Mean Before Policy & 0.54 & 0.70 & - \\
$\quad$ Implied impact of New MLDA in \% & & & -9.56 \\
& & & \\
\hline
\end{tabular}

(1) (2) (3)

VARIABLES

16-18yo 20-22yo Triple Difference

$\begin{array}{lccc}\text { Dummy policy } & -0.13^{* *} & -0.01 & -0.13 \\ & (0.05) & (0.06) & (0.09) \\ & & & \\ \text { Observations } & 100 & 103 & 99 \\ \text { R-squared } & 0.34 & 0.37 & 0.32 \\ \text { Mean Before Policy } & 0.38 & 0.55 & - \\ \quad \text { Implied impact of New MLDA in \% } & & & -33.88\end{array}$

Note: Region and Year fixed effects included. Clustered standard errors using wild bootstrap method (400 reps, 200 seeds), in parentheses. ${ }^{* *} p<0.01, * * p<0.05, * p<0.1$. Weighted by corresponding sum of populations (16-18yo $\left.+20-22 y o\right)$ per each region, and year. Source: Encuesta de Nacional de Salud (ENS): 1993; 1995; 1997; 2001; 2003(2004); 2006(2007). Ministerio de Sanidad, Servicios Sociales e Igualdad 


\subsection{Drink type Prevalence}

Table 2: Mixed drinks and/or Liquors Drinking Prevalence

Panel A: Both Genders

\begin{tabular}{lccc}
\hline & $(1)$ & $(2)$ & $(3)$ \\
VARIABLES & $16-18 y o$ & $20-22$ yo & Triple Difference \\
\hline Dummy policy & $-0.13^{*}$ & 0.00 & -0.11 \\
& $(0.07)$ & $(0.08)$ & $(0.09)$ \\
Observations & 90 & 91 & 85 \\
R-squared & 0.60 & 0.61 & 0.25 \\
Mean Before Policy & 0.43 & 0.48 & - \\
$\quad$ Implied impact of New MLDA in \% & & & -24.76 \\
\hline
\end{tabular}

Panel B: Males

\begin{tabular}{lccc}
\hline & $(1)$ & $(2)$ & $(3)$ \\
VARIABLES & $16-18 \mathrm{yo}$ & $20-22 \mathrm{yo}$ & Triple Difference \\
\hline Dummy policy & $-0.18^{*}$ & 0.06 & $-0.21^{* *}$ \\
& $(0.09)$ & $(0.06)$ & $(0.09)$ \\
Observations & 88 & 85 & 82 \\
R-squared & 0.60 & 0.71 & 0.35 \\
Mean Before Policy & 0.47 & 0.53 & - \\
$\quad$ Implied impact of New MLDA in \% & & & -44.43 \\
\hline
\end{tabular}

Panel C: Females

\begin{tabular}{lccc}
\hline & $(1)$ & $(2)$ & $(3)$ \\
VARIABLES & $16-18 y o$ & $20-22$ yo & Triple Difference \\
\hline Dummy policy & 0.08 & -0.10 & 0.24 \\
& $(0.16)$ & $(0.09)$ & $(0.21)$ \\
Observations & 78 & 86 & 75 \\
R-squared & 0.41 & 0.40 & 0.42 \\
Mean Before Policy & 0.36 & 0.43 & - \\
$\quad$ Implied impact of New MLDA in \% & & & 66.79
\end{tabular}

Note: Region and Year fixed effects included. Clustered standard errors using wild bootstrap method (400 reps, 200 seeds), in parentheses. ${ }^{* * *} p<0.01,{ }^{* *} p<0.05, * p<0.1$. Weighted by corresponding sum of populations (16-18yo $\left.+20-22 y o\right)$ per each region, and year. Source: Encuesta de Nacional de Salud (ENS): 1993; 1995; 1997; 2001; 2003(2004); 2006(2007). Ministerio de Sanidad, Servicios Sociales e Igualdad.

Firstly, Table 2 for the mixed drinks and/or liquors case shows in first column in Panel A and B significant reductions in the consumption of mixed drinks and liquors as a result of the increase in the MDLA for the treatment group. Second columns corresponding to our falsification tests show no effect for any control group. Panels $B$ and $C$ show that this effect is entirely driven by the male subsample with a Triple Difference estimated coefficient of -0.21 , statistically significant at the $5 \%$ level, corresponding to a drop in mixed drinks and/or liquors consumption of $44.43 \%$ as a result of the implementation of the policy.

Secondly, for the beer with alcohol case, Table A2 in Appendix Section A, shows no statistically significant coefficient in any of the panels pointing towards null effects on the probability of drinking beer 
with alcohol due to policy implementation. Thirdly, for the wine and/or cava drinking prevalence case, although first column of Panels A, B and C in Table A3 included in Appendix Section A, shows significant reductions in the consumption of these drinks for the three subsamples, and falsification tests for the subsample of males and the subsamples of females point to null effects for control groups, none of the Triple Difference estimated coefficients are statistically significant. Figures B3, B4, and B5, in Appendix Section B, illustrate time trends of the consumption of all drink types studied.

\subsection{Morbidity Outcomes}

Table 3: Incidence of Hospitalizations by MDALC (per 1000 individuals) Panel A: Both Genders

\begin{tabular}{lccc}
\hline & $(1)$ & $(2)$ & $(3)$ \\
VARIABLES & $16-18 \mathrm{yo}$ & $20-22 \mathrm{yo}$ & Triple Difference \\
\hline Dummy policy & -0.002 & $0.059^{* *}$ & $-0.058^{* *}$ \\
& $(0.260)$ & $(0.029)$ & $(0.029)$ \\
Observations & 184 & 191 & 183 \\
R-squared & 0.500 & 0.494 & 0.269 \\
Mean Before Policy & 0.17 & 0.31 & - \\
$\quad$ Implied impact of New MLDA in \% & & & -34.09 \\
\hline
\end{tabular}

Panel B: Males

\begin{tabular}{lccc}
\hline & $(1)$ & $(2)$ & $(3)$ \\
VARIABLES & $16-18 y o$ & $20-22 y o$ & Triple Difference \\
\hline Dummy policy & 0.016 & $0.098^{* *}$ & $-0.079^{*}$ \\
& $(0.016)$ & $(0.045)$ & $(0.043)$ \\
Observations & 172 & 187 & 172 \\
R-squared & 0.392 & 0.438 & 0.243 \\
Mean Before Policy & 0.18 & 0.43 & - \\
$\quad$ Implied impact of New MLDA in \% & & & -44.05 \\
\hline
\end{tabular}

Panel C: Females

\begin{tabular}{lccc}
\hline & $(1)$ & $(2)$ & $(3)$ \\
VARIABLES & $16-18 y o$ & $20-22 y o$ & Triple Difference \\
\hline Dummy policy & -0.017 & 0.018 & -0.034 \\
& $(0.027)$ & $(0.021)$ & $(0.037)$ \\
Observations & 170 & 178 & 161 \\
R-squared & 0.429 & 0.458 & 0.136 \\
Mean Before Policy & 0.19 & 0.22 & - \\
$\quad$ Implied impact of New MLDA in \% & & & -17.89
\end{tabular}

Note: MDALC stands for Main diagnostic related to alcohol consumption. Region and Year fixed effects included. Clustered standard errors using wild bootstrap method (400 reps, 200 seeds), in parentheses. ${ }^{* * *} p<0.01, * * p<0.05,{ }^{*} p<0.1$. Weighted by corresponding sum of populations (16-18yo $+20-22$ yo) per each region, and year. Source: Encuesta de Mordilidad Hospitalaria (EMH): 1993-2007. Ministerio de Sanidad, Servicios Sociales e Igualdad. 
Firstly, Table 3 shows estimated coefficients for the Incidence of Hospitalization by MDALC (per 1000 individuals) case.

Panel $A$, on the one hand, shows an insignificant result for the first model corresponding to the treated group. On the other hand, the second column corresponding to the model regarding the falsification test shows a positive statistically significant estimated coefficient. Consequently, we cannot interpret the third column results as evidence of the effect of the policy on our treated group. Similar results can be observed in Panel B for the subsample of males as the coefficient for the treated group is not significant and the falsification test is not passed either. Finally, Panel $C$ for the subsample of females shows a negative coefficient for the treated group suggesting that females reduced the hospitalization incidence as a result of the implementation of the policy although the coefficient is not significant.

Secondly, regarding the case of incidence of hospitalizations by traffic accidents (per 1000 individuals), Table A4 in Appendix Section A, shows no statistically significant results for any of our coefficients of interest shown in third column corresponding to our Triple Difference model. Figures B6 and B7 in Appendix Section B show the evolution of these morbidity outcomes for years before, during, and after the policy implementation.

\section{Discussion}

First of all, we find a causal reduction of $21.37 \%$ in overall drinking prevalence for the subsample that includes males and females. This effect is mainly driven by a reported reduction of $44.43 \%$ in mixed drinks and/or liquors drinking prevalence for the subsample of males. No effects with regard to overall smoking prevalence were found. These findings point in the same direction as those provided by Carpenter and Dobkin (2011) and Yörük and Yörük (2011) for drinking related variables, and Carpenter and Dobkin (2009) regarding null effects on smoking.

Secondly, although we find Triple Difference statistically significant coefficients for hospitalizations due to alcohol overdose, treated group reported null effects and control groups did not pass the falsification tests. On these grounds we cannot argue causality. With respect to the reported null effect on traffic accidents it is noteworthy to bear in mind that in Spain the minimum age for driving is 18.

We argue that the main mechanism of transmission of this policy is closely related to binge drinking in public spaces, known as "botellón" ${ }^{5}$. This practice is quite popular amongst teenagers and young adults, specially during weekends and holidays with a predominance of consumption of mixed drinks. We suggest that absence of regulation with respect to drinking on public places for adults during the timespan of this study ${ }^{6}$ and budget constraints between these individuals play a key role in consuming alcoholic drinks outside pubs and clubs where access is strictly restricted for those under 18 and prices per drink are much higher.

Based on these results, we argue that the enforcement devices accompanying the New MLDA such as administrative penalties and/or fines on both sides of the market exerted an important effect on compliance and caused a reduction in alcohol consumption for the target group. These effects can be considered as a lower bound given the usual limitations of surveys of this sort (i.e. underreporting).

\section{Conclusions}

Our findings provide evidence to argue that shifting the MLDA from 16 to 18 years old can have substantial public health benefits. To our knowledge we are the first to provide evidence regarding genderbased differences related to policies aimed at reducing alcohol consumption. These results suggest that the inclusion of gender perspectives in the process of policy design can contribute to identify more effective policy levers. Furthermore, a quite interesting exercise would be to assess the findings of this study to those that could be obtained from a more focused set of surveys such as the Survey on Alcohol and other Drugs in

\footnotetext{
${ }^{5}$ Also known in some regions as "Hacer litros", "Botelleo", or "Comprar un lote".

${ }^{6}$ Nowadays, we can find different kinds of regional regulations for adults drinking in public spaces.
} 
Spain (Encuesta sobre alcohol y otras drogas en España, EDADES) ${ }^{7}$. We believe our results have important policy implications for countries currently considering changes in the Minimum Legal Drinking Age. If this reduction had an impact on performance on standardized tests or crime rate, remains as key topics for future research.

7 Access to these survey-microdata still not granted. See http://www.pnsd.msssi.gob.es/profesionales/ sistemasInformacion/sistemalnformacion/encuestas_EDADES.htm (Last accessed March 27th 2018). 


\section{References}

Bertrand, M., Duflo, E., \& Mullainathan, S. (2004). How much should we trust differences-indifferences estimates? The Quarterly Journal of Economics, 119(1), 249-275. Retrieved from http://dx.doi.org/10.1162/003355304772839588 doi: 10.1162/003355304772839588

Carpenter, C. (2004a). Heavy alcohol use and youth suicide: evidence from tougher drunk driving laws. Journal of Policy Analysis and Management, 23(4), 831-842. Retrieved from https:// doi.org/10.1002/pam.20049 doi: 10.1002/pam.20049

Carpenter, C. (2004b). How do zero tolerance drunk driving laws work? Journal of Health Economics, 23(1), 61-83. Retrieved from https://doi.org/10.1016/j.jhealeco.2003.08.005 doi: 10 $.1016 /$ j.jhealeco.2003.08.005

Carpenter, C. (2005). Heavy alcohol use and the commission of nuisance crime: Evidence from underage drunk driving laws. American Economic Review, 95(2), 267-272. Retrieved from http://www.aeaweb.org/articles?id=10.1257/000282805774670220 doi: 10.1257/ 000282805774670220

Carpenter, C. (2007). Heavy alcohol use and crime: evidence from underage drunk-driving laws. The Journal of Law and Economics, 50(3), 539-557. Retrieved from https://doi.org/10.1086/ 519809 doi: $10.1086 / 519809$

Carpenter, C., \& Dobkin, C. (2009). The effect of alcohol consumption on mortality: regression discontinuity evidence from the minimum drinking age. American Economic Journal: Applied Economics, 1(1), 164182.

Carpenter, C., \& Dobkin, C. (2011). The minimum legal drinking age and public health. Journal of Economic Perspectives, 25(2), 133-56. Retrieved from http://www.aeaweb.org/articles?id= 10.1257/jep.25.2.133 doi: 10.1257/jep.25.2.133

Dee, T. S. (1999). State alcohol policies, teen drinking and traffic fatalities. Journal of Public Economics, 72(2), 289-315. Retrieved from https://doi.org/10.1016/S0047-2727(98)00093 -0 doi: 10.1016/S0047-2727(98)00093-0

Deza, M. (2015). The effects of alcohol on the consumption of hard drugs: regression discontinuity evidence from the national longitudinal study of youth, 1997. Health economics, 24(4), 419-438.

Retrieved from https://doi.org/10.1002/hec.3027 doi: 10.1002/hec.3027

Mann, R. E., Smart, R. G., \& Govoni, R. (2003). The epidemiology of alcoholic liver disease. Alcohol Research and Health, 27, 209-219.

Markowitz, S. (2000). The price of alcohol, wife abuse, and husband abuse. Southern Economic Journal, 67(2), 279-303. Retrieved from https://www.jstor.org/stable/1061471 doi: 10 $.2307 / 1061471$

Markowitz, S. (2005). Alcohol, drugs and violent crime. International Review of Law and Economics, 25(1), 20-44. Retrieved from https://doi.org/10.1016/j.irle.2005.05.003 doi: 10.1016/ j.irle.2005.05.003

Martín San Juan, C. (2013). Effectiveness of Minimum Drinking Age Laws on Youth Alcohol Consumption. Spanish Case Study (End of Degree Project). Universidad Carlos III, Madrid - Spain.

Observatorio Español de las Drogas y las Adicciones (OEDT). Ministerio de Sanidad y Servicios Sociales e Igualdad. (2016). La Encuesta sobre uso de drogas en Enseñanzas Secundarias en España (ESTUDES) 2014/2015. Retrieved from http://www.sepg.pap.minhafp.gob.es/ sitios/sepg/esES/Presupuestos/PresupuestosEjerciciosAnteriores/Paginas/

Ejercicio2016.aspx

Rosenberg, H. M., Ventura, S. J., Maurer, J. D., Heuser, R. L., \& Freedman, M. A. (1996). Births and deaths: United states, 1995. Monthly vital statistics report, 45(3), 2.

Wagenaar, A. C., \& Toomey, T. L. (2002). Effects of minimum drinking age laws: review and analyses of the literature from 1960 to 2000. Journal of Studies on Alcohol, Supplement(s14),

206-225. Retrieved from https://doi.org/10.15288/jsas.2002.s14.206 doi: 10.15288/ jsas.2002.s14.206 
Yörük, B. K., \& Yörük, C. E. (2011). The impact of minimum legal drinking age laws on alcohol consumption, smoking, and marijuana use: Evidence from a regression discontinuity design using exact date of birth. Journal of Health Economics, 30(4), 740-752. Retrieved from https:// doi.org/10.1016/j.jhealeco.2011.05.010 doi: 10.1016/j.jhealeco.2011.05.010

Yörük, B. K., \& Yörük, C. E. (2013). The impact of minimum legal drinking age laws on alcohol consumption, smoking, and marijuana use revisited. Journal of Health Economics, 32(2), 477-

479. Retrieved from https://doi.org/10.1016/j.jhealeco.2012.09.007 doi: 10.1016/ j.jhealeco.2012.09.007 


\section{Appendices [Online]}

\section{Appendix A: Auxiliary Results}

\subsection{Tables - Overall Smoking Prevalence}

Table A1: Overall Smoking Prevalence

Panel A: Both Genders

(1) (2)

(3)

\begin{tabular}{lccc}
\hline VARIABLES & $(1)$ & $(2)$ & $(3)$ \\
\hline Dummy policy & $16-18$ yo & $20-22$ yo & Triple Difference \\
& -0.05 & -0.04 & -0.01 \\
Observations & $(0.05)$ & $(0.03)$ & $(0.05)$ \\
R-squared & 104 & 104 & 104 \\
Mean Before Policy & 0.40 & 0.27 & 0.17 \\
Implied impact of New MLDA in \% & 0.35 & 0.49 & - \\
& & & -4.05 \\
& Panel B: Males & & \\
\hline & $(1)$ & $(2)$ & $(3)$ \\
VARIABLES & $16-18 y o$ & $20-22 y o$ & Triple Difference \\
\hline Dummy policy & -0.04 & -0.03 & -0.01 \\
& $(0.04)$ & $(0.05)$ & $(0.05)$ \\
Observations & 104 & 103 & 103 \\
R-squared & 0.35 & 0.27 & 0.23 \\
Mean Before Policy & 0.35 & 0.48 & - \\
Implied impact of New MLDA in \% & & & -1.96 \\
& & & \\
\hline
\end{tabular}

Panel C: Females

(1) (2)

(3)

VARIABLES

16-18yo 20-22yo Triple Difference

\begin{tabular}{lccc}
\hline Dummy policy & -0.06 & -0.07 & 0.01 \\
& $(0.07)$ & $(0.08)$ & $(0.11)$ \\
Observations & 100 & 103 & 99 \\
R-squared & 0.24 & 0.20 & 0.17 \\
Mean Before Policy & 0.33 & 0.50 & - \\
$\quad$ Implied impact of New MLDA in \% & & & 3.63
\end{tabular}

Note: Region and Year fixed effects included. Clustered standard errors using wild bootstrap method (400 reps, 200 seeds), in parentheses. ${ }^{* * *} p<0.01,{ }^{* *} p<0.05, * p<0.1$. Weighted by corresponding sum of populations (16-18yo $\left.+20-22 y o\right)$ per each region, 
and year. Source: Encuesta de Nacional de Salud (ENS): 1993; 1995; 1997; 2001; 2003(2004); 2006(2007). Ministerio de Sanidad, Servicios Sociales e Igualdad.

Table A2: Beer with alcohol Drinking Prevalence

Panel A: Both Genders

\begin{tabular}{lccc}
\hline & $(1)$ & $(2)$ & $(3)$ \\
VARIABLES & $16-18$ yo & $20-22$ yo & Triple Difference \\
\hline \multirow{2}{*}{ Dummy policy } & 0.03 & -0.01 & 0.05 \\
& $(0.07)$ & $(0.03)$ & $(0.08)$ \\
& & & \\
Observations & 101 & 103 & 101 \\
R-squared & 0.64 & 0.47 & 0.29 \\
Mean Before Policy & 0.72 & 0.77 & - \\
$\quad$ Implied impact of New MLDA in \% & & & 7.05 \\
\hline
\end{tabular}

Panel B: Males

\begin{tabular}{lccc}
\hline & $(1)$ & $(2)$ & $(3)$ \\
VARIABLES & $16-18$ yo & $20-22$ yo & Triple Difference \\
\hline Dummy policy & 0.00 & -0.02 & 0.03 \\
& $(0.01)$ & $(0.07)$ & $(0.03)$ \\
Observations & 101 & 102 & 100 \\
R-squared & 0.57 & 0.39 & 0.29 \\
Mean Before Policy & 0.80 & 0.86 & - \\
$\quad$ Implied impact of New MLDA in \% & & & 3.81 \\
\hline
\end{tabular}

Panel C: Females

\begin{tabular}{lccc}
\hline & $(1)$ & $(2)$ & $(3)$ \\
VARIABLES & $16-18$ yo & $20-22$ yo & Triple Difference \\
\hline Dummy policy & -0.03 & -0.09 & 0.07 \\
& $(0.14)$ & $(0.08)$ & $(0.15)$ \\
Observations & 90 & 100 & 89 \\
R-squared & 0.45 & 0.37 & 0.25 \\
Mean Before Policy & 0.61 & 0.67 & - \\
$\quad$ Implied impact of New MLDA in \% & & & 10.88
\end{tabular}

Note: Region and Year fixed effects included. Clustered standard errors using wild bootstrap method (400 reps, 200 seeds), in parentheses. ${ }^{* * *} \mathrm{p}<0.01,{ }^{* *} \mathrm{p}<0.05,{ }^{*} \mathrm{p}<0.1$. Weighted by corresponding sum of populations $(16-18 \mathrm{yo}+20-22 \mathrm{yo})$ per each region, and year. Source: Encuesta de Nacional de Salud (ENS): 1993; 1995; 1997; 2001; 2003(2004); 2006(2007). Ministerio de Sanidad, Servicios Sociales e Igualdad. 
Table A3: Wine and/or Cava Drinking Prevalence

Panel A: Both Genders

(1) (2) (3)

VARIABLES

16-18yo 20-22yo Triple Difference

Dummy policy

$\begin{array}{lll}-0.17^{* * *} & -0.12^{*} & -0.05 \\ (0.06) & (0.06) & (0.07)\end{array}$

Observations

$97 \quad 101 \quad 96$

R-squared

$0.56 \quad 0.42$

0.40

Mean Before Policy

$0.49 \quad 0.51$

Implied impact of New MLDA in \%

$-10.55$

Panel B: Males

(1) (2)

(3)

VARIABLES

16-18yo 20-22yo Triple Difference

Dummy policy

$\begin{array}{lll}-0.15^{* * *} & -0.10 & -0.07 \\ (0.05) & (0.09) & (0.09)\end{array}$

$\begin{array}{lccc}\text { Observations } & 96 & 98 & 93 \\ \text { R-squared } & 0.52 & 0.44 & 0.28 \\ \text { Mean Before Policy } & 0.48 & 0.55 & -\end{array}$

Implied impact of New MLDA in \%

$-14.23$

Panel C: Females

(1) (2)

(3)

\begin{tabular}{lccc} 
VARIABLES & $16-18 y o$ & $20-22 y o$ & Triple Difference \\
\hline Dummy policy & $-0.17^{* *}$ & -0.13 & -0.06 \\
& $(0.08)$ & $(0.12)$ & $(0.15)$ \\
& & & \\
Observations & 89 & 97 & 86 \\
R-squared & 0.53 & 0.39 & 0.30 \\
Mean Before Policy & 0.51 & 0.47 & - \\
Implied impact of New MLDA in \% & & & -11.75
\end{tabular}

Note: Region and Year fixed effects included. Clustered standard errors using wild bootstrap method (400 reps, 200 seeds), in parentheses. ${ }^{* *} p<0.01,{ }^{* *} p<0.05, * p<0.1$. Weighted by corresponding sum of populations (16-18yo $\left.+20-22 y o\right)$ per each region, and year. Source: Encuesta de Nacional de Salud (ENS): 1993; 1995; 1997; 2001; 2003(2004); 2006(2007). Ministerio de Sanidad, Servicios Sociales e Igualdad. 


\subsection{Tables - Other Morbidity Outcomes}

Table A4: Incidence of Hospitalizations by Traffic Accidents (per 1000 individuals)

Panel A: Both Genders

\begin{tabular}{lccc}
\hline & $(1)$ & $(2)$ & $(3)$ \\
VARIABLES & $16-18$ yo & $20-22$ yo & Triple Difference \\
\hline \multirow{2}{*}{ Dummy policy } & 0.032 & $0.081^{* *}$ & -0.062 \\
& $(0.030)$ & $(0.036)$ & $(0.047)$ \\
& & & \\
Observations & 158 & 160 & 154 \\
R-squared & 0.786 & 0.872 & 0.488 \\
Mean Before Policy & 0.35 & 0.32 & - \\
$\quad$ Implied impact of New MLDA in \% & & & -17.81 \\
\end{tabular}

Panel B: Males

\begin{tabular}{lccc}
\hline & $(1)$ & $(2)$ & $(3)$ \\
VARIABLES & $16-18$ yo & $20-22$ yo & Triple Difference \\
\hline Dummy policy & 0.007 & $0.122^{* *}$ & -0.116 \\
& $(0.054)$ & $(0.052)$ & $(0.098)$ \\
Observations & 156 & 156 & 152 \\
R-squared & 0.844 & 0.853 & 0.513 \\
Mean Before Policy & 0.58 & 0.52 & - \\
$\quad$ Implied impact of New MLDA in \% & & & -19.97 \\
\hline
\end{tabular}

Panel C: Females

(1) (2) (3)

VARIABLES

16-18yo 20-22yo Triple Difference
Dummy policy

$0.039 \quad 0.041$

(0.026) (0.027)

$137 \quad 140$

$0.701 \quad 0.717$

$0.13 \quad 0.14$

$-0.014$

(0.034)

$\begin{array}{lccc}\text { Observations } & 137 & 140 & 128 \\ \text { R-squared } & 0.701 & 0.717 & 0.313 \\ \text { Mean Before Policy } & 0.13 & 0.14 & -\end{array}$

Implied impact of New MLDA in \%
$-10.97$

Note: MDALC stands for Main diagnostic related to alcohol consumption. Region and Year fixed effects included. Clustered standard errors using wild bootstrap method ( 400 reps, 200 seeds), in parentheses. ${ }^{* * *} p<0.01,{ }^{* *} p<0.05,{ }^{*} p<0.1$. Weighted by corresponding sum of populations (16-18yo $+20-22$ yo) per each region, and year. Source: Encuesta de Mordilidad Hospitalaria (EMH): 1993-2007. Ministerio de Sanidad, Servicios Sociales e Igualdad. 


\section{Appendix B: Auxiliary Figures}

\section{Figures - Overall prevalence}

Figure B1: Trends - Overall drinking prevalence

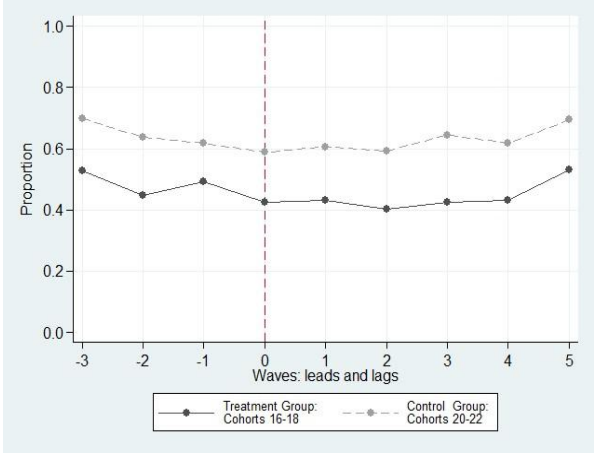

(a) Both genders

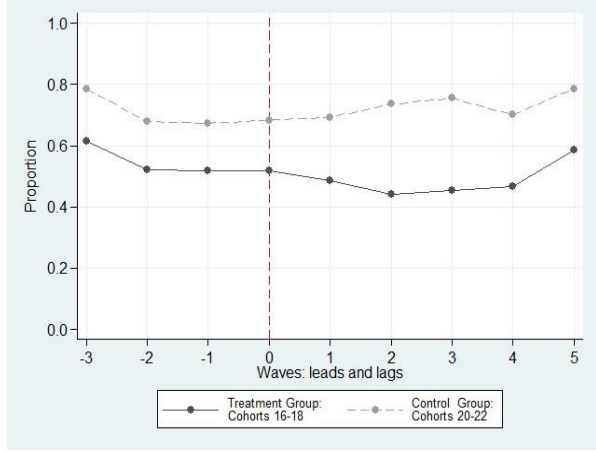

(b) Males

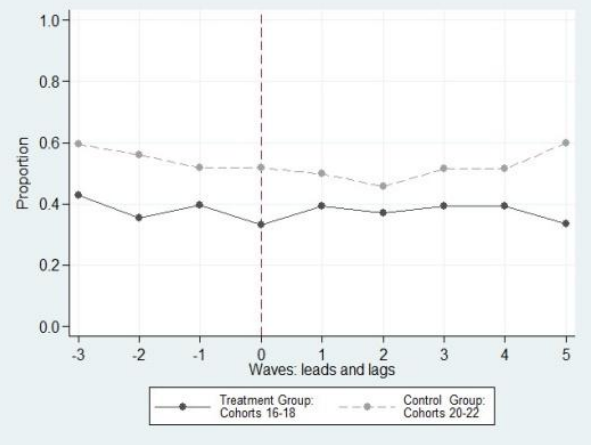

(c) Females

Note: MLDA stands for Minimum Legal Drinking Age. Source: Ministerio de Sanidad y Asuntos Sociales.

Figure B2: Trends - Overall smoking prevalence

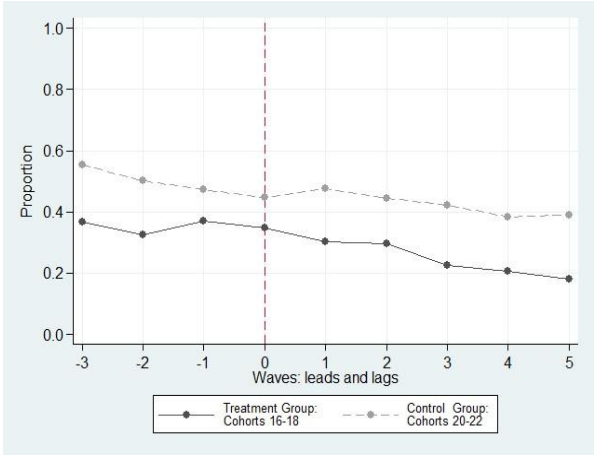

(a) Both genders

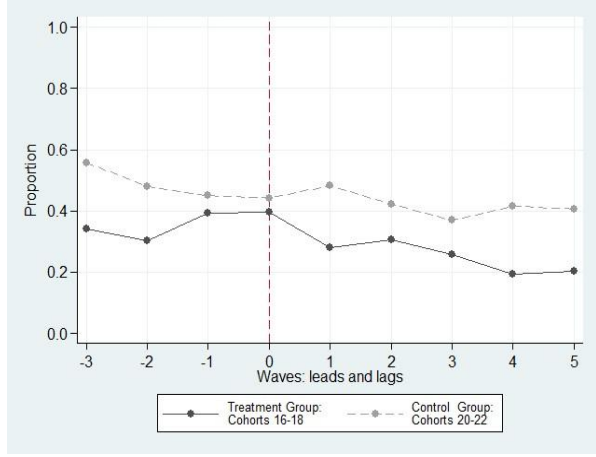

(b) Males

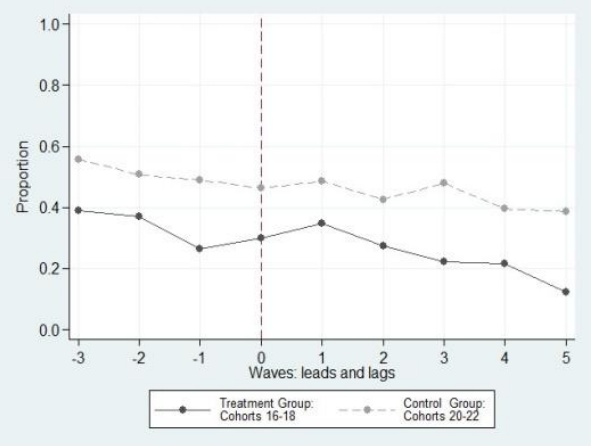

(c) Females

Note: MLDA stands for Minimum Legal Drinking Age. Source: Ministerio de Sanidad y Asuntos Sociales. 
Figure B3: Trends - Beer with alcohol drinking prevalence

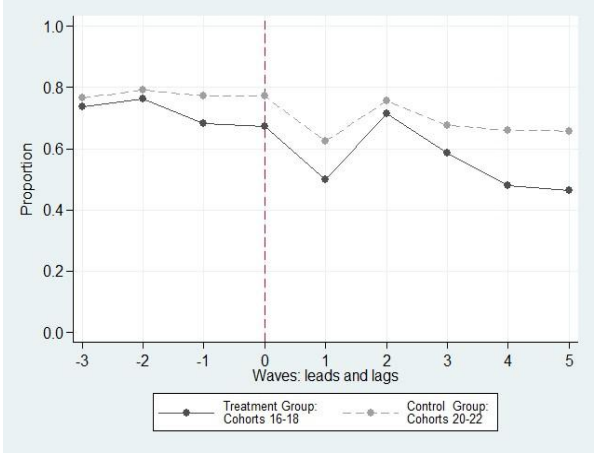

(a) Both genders

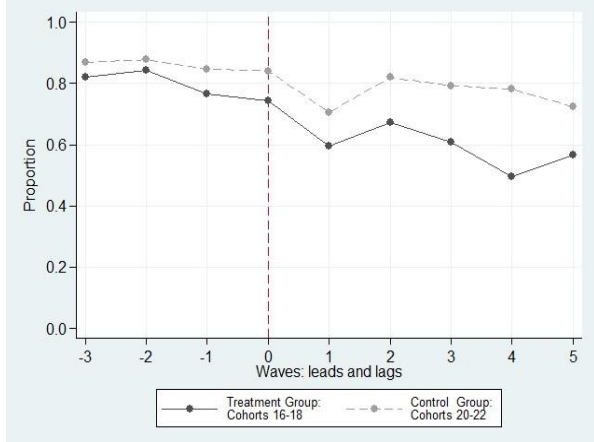

(b) Males

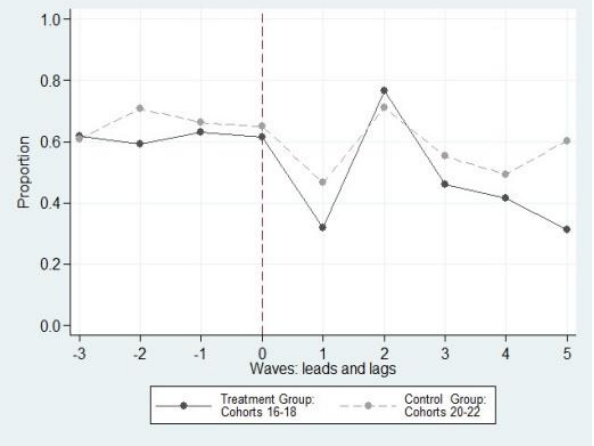

(c) Females

Note: MLDA stands for Minimum Legal Drinking Age. Source: Ministerio de Sanidad y Asuntos Sociales.

Figure B4: Trends - Mixed drinks and/or Liquors drinking prevalence

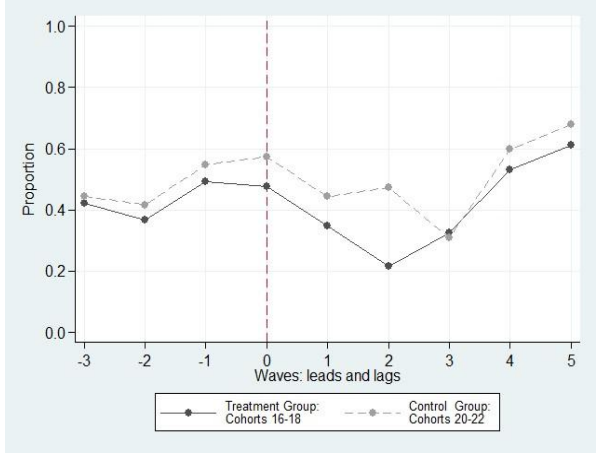

(a) Both genders

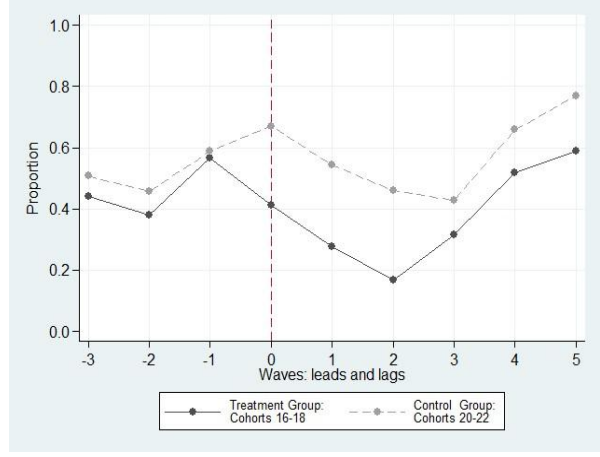

(b) Males

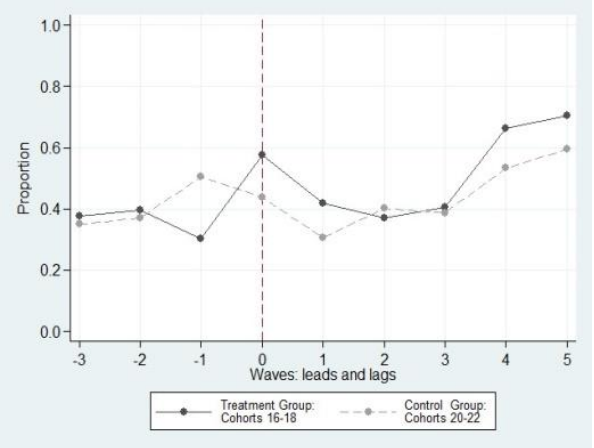

(c) Females

Note: MLDA stands for Minimum Legal Drinking Age. Source: Ministerio de Sanidad y Asuntos Sociales. 
Figure B5: Trends - Wine and/or Cava drinking prevalence

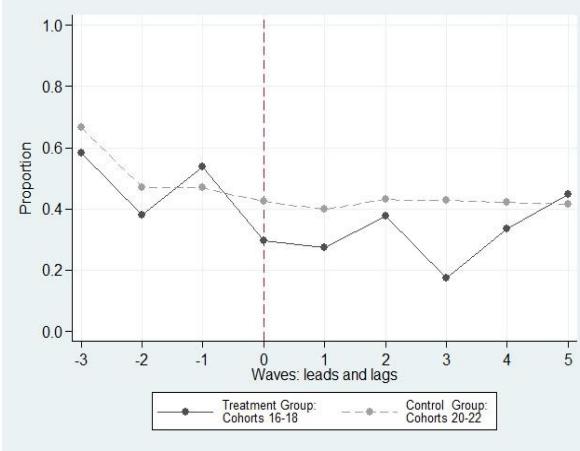

(a) Both genders

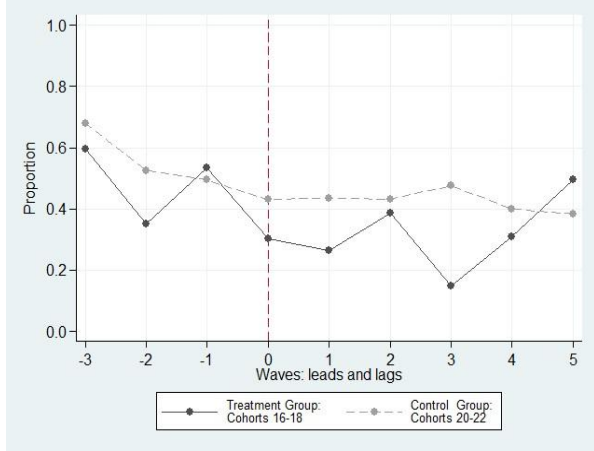

(b) Males

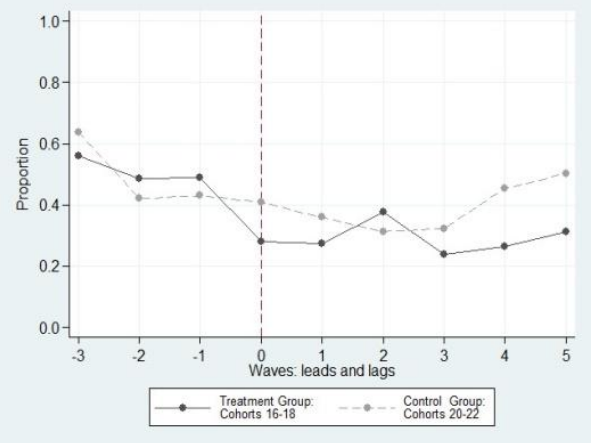

(c) Females

Note: MLDA stands for Minimum Legal Drinking Age. Source: Ministerio de Sanidad y Asuntos Sociales.

\section{Figures - Morbidity Outcomes}

Figure B6: Trends - Ratio Hospitalizations by MDALC/Population (per 1000 individuals)

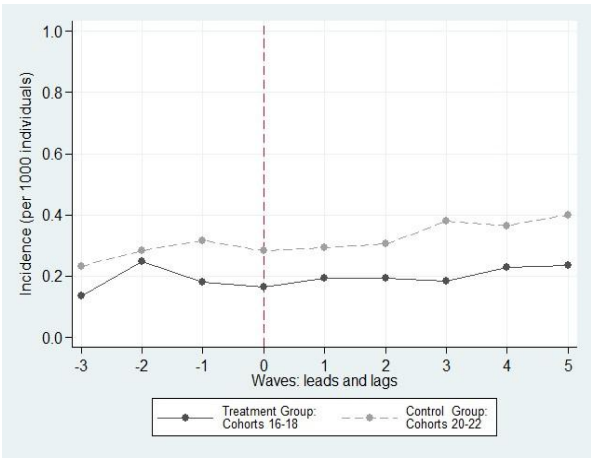

(a) Both genders

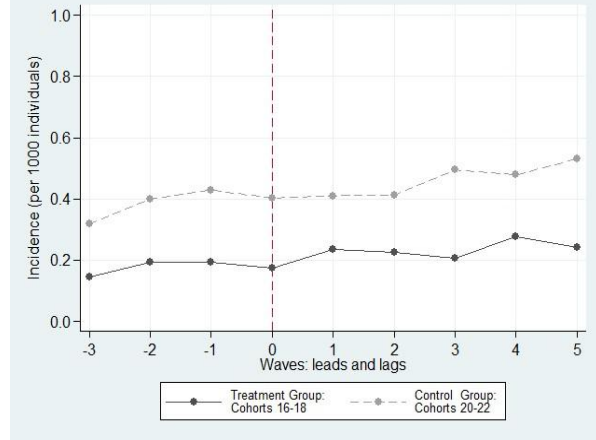

(b) Males

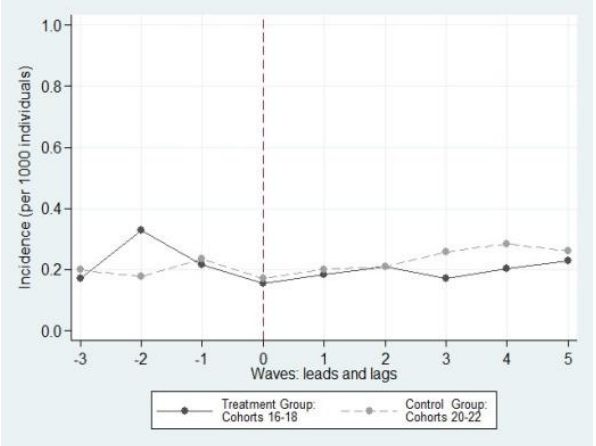


Note: MDALC stands for Mean diagnostic related to alcohol consumption. Source: Ministerio de Sanidad y Asuntos Sociales.

Figure B7: Trends - Ratio Hospitalizations by Traffic Accidents/Population (per 1000 individuals)

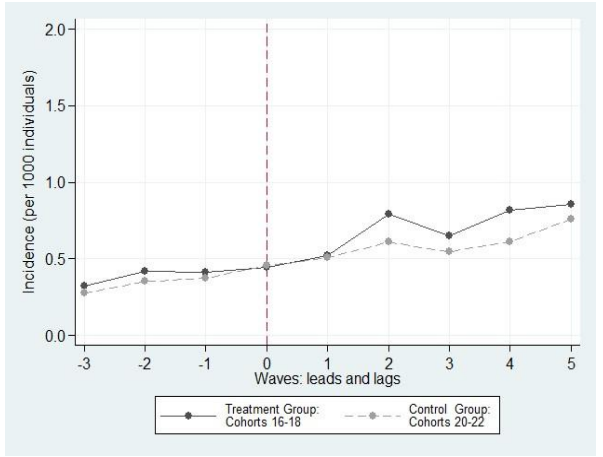

(a) Both genders

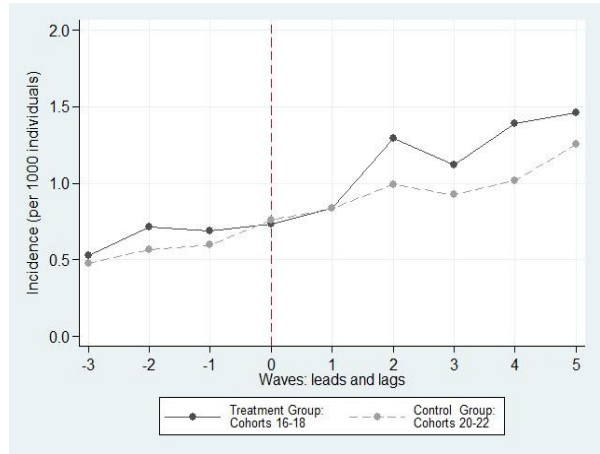

(b) Males

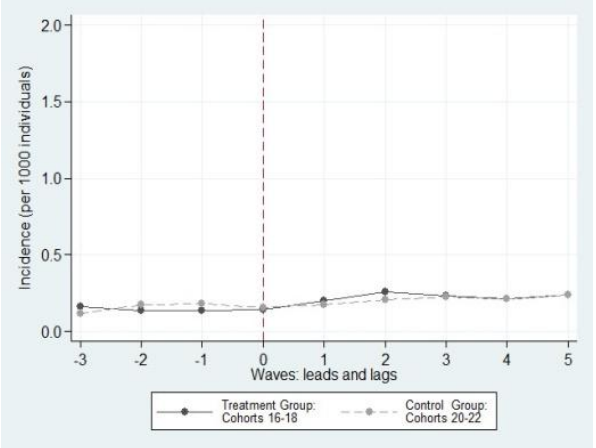

(c) Females

Note: MDALC stands for Mean diagnostic related to alcohol consumption. Source: Ministerio de Sanidad y Asuntos Sociales. 
Appendix C: Auxiliary Tables

Table C1: Spain - Implementation of New MLDA in all seventeen regions

\begin{tabular}{|c|c|c|}
\hline Region & $\begin{array}{l}\text { Date of implementation } \\
\text { Chronologically ordered }\end{array}$ & Official Bulletin \\
\hline Navarra $^{+}$ & April 6th, 1991 & BOE-A-1991-23614 \\
\hline \multirow[t]{2}{*}{ Castilla y León } & April 7th, 1994 (partial ban) & BOCL nm. 65, de 6 de abril de 1994 \\
\hline & June 14th, 2007 (full ban) & BOCL nm. 52, de 14 de marzo de 2007 \\
\hline Castilla-La Mancha & April 22nd, 1995 & $\begin{array}{l}\text { Diario Oficial de Castilla-La Mancha núm. 19, } \\
\text { de } 21 \text { de abril de } 1995\end{array}$ \\
\hline Andalucía & July 20th, 1997 & BOE-A-1997-18301 \\
\hline Canarias & February 18th, 1997 & BOE-A-1997-5498 \\
\hline Cantabria & November 15th, 1997 & $\begin{array}{l}\text { Boletín Oficial de Cantabria núm. 205, de } \\
14 \text { de noviembre de } 1997\end{array}$ \\
\hline \multirow[t]{2}{*}{ C. Valenciana } & June 19th, 1997 (partial ban) & $\begin{array}{l}\text { Diario Oficial de la Generalitat Valenciana } \\
\text { núm. 3.016, de } 18 \text { de junio de } 1997\end{array}$ \\
\hline & August 27th, 2002 (full ban) & BOE-A-2002-14189 \\
\hline Extremadura & May 18th, 1997 & $\begin{array}{l}\text { Diario Oficial de Extremadura núm. } \\
\text { 57, de } 17 \text { de mayo de } 1997\end{array}$ \\
\hline Murcia & November 13th, 1997 & BOE-A-1998-3169 \\
\hline País Vasco & July 15th, 1998 & BOE-A-2011-20661 \\
\hline Madrid & May 12th, 2000 & BOE-A-2000-9793 \\
\hline Aragón & May 1st, 2001 & BOE-A-2001-9342 \\
\hline La Rioja & February 18th, 2001 & BOE-A-2000-21563 \\
\hline Cataluña & April 8th, 2002 & DOGC nm. 3598, de 19 de marzo de 2002 \\
\hline Galicia $^{+}$ & February 28th, 2011 & BOE-A-2011-1647 \\
\hline Baleares $^{+}$ & February 28th, 2014 & BOE-A-2014-655 \\
\hline Asturias $^{+}$ & May 20th, 2015 & BOE-A-2015-4847 \\
\hline
\end{tabular}

Note: $\mathrm{MLDA}=$ Minimum Legal Drinking Age. BOE = Boletín Oficial del Estado (National Official Bulletin). $\mathrm{BOCL}=$ Boletín Oficial de Castilla y León (Official Bulletin of Region of Castilla y León). DOGC = Diario Oficial de la Generalitat de Catalunya (Official Bulletin of the Region of Catalunya). ${ }^{+}$Data for these regions was not used because New MLDA was implemented outside the 1993-2007 inclusive range of years. Source: Official Bulletins. 
Table C2: National Health Survey and Hospital Morbidity Survey Summary of Descriptive Statistics

Panel A: National Health Survey (ENS) - Prevalence

(8) waves included

\begin{tabular}{lcccc} 
& count & mean & $\min$ & $\max$ \\
\hline Dummy gender: 0=Females; 1= Males & 104 & 0.52 & 0 & 1 \\
Have you drunk during the last 2 weeks? & 104 & 0.54 & 0 & 1 \\
Do you smoke nowadays? & 104 & 0.36 & 0 & 1 \\
Do you drink beer with alcohol? & 103 & 0.67 & 0 & 1 \\
Do you drink mixed drinks and/or liquors? & 96 & 0.48 & 0 & 1 \\
Do you drink wine and/or cava? & 102 & 0.41 & 0 & 1
\end{tabular}

Panel B: Hospital Morbidity Survey (EMH) - Incidence (per 1000 hab.)

(15) waves included

count mean min $\max$

$\begin{array}{lllll}\text { Hospitalizations due to MDALC } & 192 & 0.26 & 0.02 & 0.83 \\ \text { Hospitalizations due to Traffic Accidents } & 164 & 0.50 & 0.00 & 1.40\end{array}$

Note: 13 out 17 regions were included. Excluded (4) regions did not have enough data for waves before or after policy implementation. Treated and control group included cohorts 16-18 years old and cohorts 2022 years old, respectively. Unit of observation at the regional-year level. Panel A: Encuesta Nacional de Salud (ENS): Waves 1993, 1995, 1997 and 2001 were prepared by the Centre of Sociological Research. Waves 2003(2004) and 2006(2007) were prepared by the National Institute of Statistics (INE). Panel B: Encuesta de Morbilidad Hospitalaria (EMH): all waves 1993-2007 were prepared by the National Institute of Statistics (INE). MDALC stands for Mean Diagnostic Related to Alcohol Overdose. 
A) Included in Hospitalizations regarding MDALC:

Codes: 290-319 Mental disorders

Psychosis (290-299)

Organic psychotic conditions (290-294)

(291) Alcoholic psychoses

(292) Drug psychoses

Neurotic disorders, personality disorders, and other nonpsychotic mental disorders (300-316)

Sexual deviations and disorders (302)

(302) Sexual deviations and disorders

Psychoactive substance (303-305)

(303) Alcohol dependence syndrome (Include: acute drunkenness in alcoholism, dipsomania, chronic alcoholism)

(304) Drug dependence

(305) Nondependent abuse of drugs

Codes: 520-579 Diseases of the digestive system

Other diseases of digestive system (570-579)

Liver

(570) Acute and subacute necrosis of liver

(571) Chronic liver disease and cirrhosis

(572) Liver abscess and sequelae of chronic liver disease

(573) Other disorders of liver

Codes: 800-999 Injury and poisoning

Poisoning by drugs, medicinal and biological substances (960-979)

(967) Poisoning by sedatives and hypnotics

(968) Poisoning by other Central nervous system depressants and anesthetics

(969) Poisoning by psychotropic agents

(970) Poisoning by central nervous system stimulants

(971) Poisoning by drugs primarily affecting the autonomic nervous system

(972) Poisoning by agents primarily affecting the cardiovascular system

B) Included in Hospitalizations regarding Traffic Accidents:

\section{Codes: E810-E819 Motor Vehicle Traffic Accidents}

(E810) Motor vehicle traffic accident involving collision with train

(E811) Motor vehicle traffic accident involving re-entrant collision with another motor vehicle

(E812) Other motor vehicle traffic accident involving collision with motor vehicle

(E813) Motor vehicle traffic accident involving collision with other vehicle

(E814) Motor vehicle traffic accident involving collision with pedestrian

(E815) Other motor vehicle traffic accident involving collision on the highway

(E816) Motor vehicle traffic accident due to loss of control without collision on the highway

(E817) Noncollision motor vehicle traffic accident while boarding or alighting

(E818) Other noncollision motor vehicle traffic accident

(E819) Motor vehicle traffic accident of unspecified nature 
Note: ICD-9 = International Statistical Classification of Diseases and Related Health Problems - 9th Revision. Source: Ministerio de Sanidad, Servicios Sociales e Igualdad. 